Letter to Editor

\title{
Abdominal epilepsy- A diagnosis often missed! - A case report
}

\author{
Deswal S. ${ }^{1}$, Paul P. ${ }^{2}$, Murugan S ${ }^{3}$, Yadav T.P. ${ }^{4}$ \\ ${ }^{1}$ Dr. Shivani Deswal, ${ }^{2}$ Dr. Paramita Paul, ${ }^{3}$ Dr. Murugan S., ${ }^{4}$ Dr. T.P. Yadav, all authors are affiliated with Department of \\ Pediatrics, Post Graduate Institution of Medical Education and Research and Dr. Ram Manohar Lohia Hospital, New \\ Delhi.
}

Corresponding Author: Dr. Shivani Deswal, DNB Pediatrics, Fellow (IAP GASTRO), Associate Professor, Department of Pediatrics, Post Graduate Institution of Medical Education and Research and Dr. Ram Manohar Lohia Hospital, New Delhi. Postal Address-A-805, Sispal Vihar, AWHO Society, Sector 49, Sohna Road, Gurgaon. E-mail: shivanipaeds@gmail.com

\begin{abstract}
Abdominal Epilepsy is a rare cause of recurrent abdominal pain in children. Paroxysmal episodes of pain abdomen with neurological symptoms like dizziness, post-ictal sleep or lethargy, specific electro-encephalographic changes and improvement in symptoms after treatment with antiepileptic drugs help in diagnosis of abdominal epilepsy. We report a seven-year-old girl with recurrent episodes of abdominal pain. Cause of pain remained undiagnosed despite extensive investigative workup. Meticulous history and pain diary gave clue to the diagnosis. EEG conducted during pain episode was abnormal. Treatment with Valproate resolved the pain. Normalization of EEG findings on follow up confirmed the diagnosis of abdominal epilepsy.
\end{abstract}

Key word: Paroxysmal pain abdomen; Neurological symptoms; Abdominal Epilepsy

\section{Introduction}

Recurrent bouts of abdominal pain present the clinician with a diagnostic dilemma. Apley defines recurrent abdominal pain as "at least three episodes of abdominal pain, severe enough to affect their activities over a period longer than three months"[1]. Several pathological conditions can lead to paroxysmal episodes of pain. Common organic causes include parasitic infestation, constipation, gastro-esophageal reflux disease, Helicobacter pylori, gastritis, celiac disease, urinary tract infections and surgical conditions like intestinal bands and adhesions. Less common causes are porphyria, lead poisoning, abdominal migraine, food allergy and abdominal epilepsy. Abdominal epilepsy is characterized by otherwise unexplained paroxysmal abdominal pain, other gastrointestinal complaint like vomiting, nausea, symptoms of disturbances of central nervous system like dizziness, lethargy, disorientation or post-ictal sleep, definite electroencephalogram abnormality and improvement on introduction of antiepileptic drugs [2,3]. High index of suspicion is required for diagnosis [4]. EEG abnormality and improvement on antiepileptic helps in diagnosing a case of abdominal epilepsy [5]. We present a case of sevenyear-old girl with idiopathic abdominal epilepsy.

\section{Case Report}

A seven-year-old female child presented with complaint of recurrent abdominal pain for last 7 months. It was acute onset, colicky, mostly in periumbilical region, lasting for 1-3 hours, associated with vomiting 1-2 episodes. There was no history of hiccups, water brash, bloating, loose stool, constipation, dark colored urine during pain episodes, blood in stool, any headache.

There was no past history of febrile seizure or family history of migraine, epilepsy, IBD or family discord/separation. She had undergone extensive investigations like CBC, LFT, KFT, Amylase, Lipase, stool for ova cyst, urine r/m and c/s, Xray abdomen, USGabdomen, Upper GI Endoscopy. All the investigative workup was normal. TTGIg A, urine for porphyrin, ANA were also negative. Before attending our clinic, she had received repeated deworming, treatment for

Manuscript received: $4^{\text {th }}$ November 2018

Reviewed: $14^{\text {th }}$ November 2018

Author Corrected: $20^{\text {th }}$ November 2018

Accepted for Publication: $24^{\text {th }}$ November 2018 
Letter to Editor

peptic ulcer disease and reflux, many antispasmodics and analgesics but relief of pain was minimal with these drugs. She was also given trial of flunarizine and sumatriptan for two months with possibility of abdominal migraine but pain showed no improvement. We reviewed her pain history in detail, stopped all medications for one week and asked the parents to maintain a pain diary. Neurological and other systemic examination revealed no abnormality. On follow-up, her diary revealed $2-3$ episodes of pain per day, no fixed time and after most of the episodes the child would sleep (which the parents interpreted as tiredness from pain episode during the time of history). There was also complain of dizziness in one episodeand vomiting at the beginning of few episodes. In between pain episodes the child remained normal and active. Due to high suspicion of abdominal epilepsy, an EEG was done during pain episode. It revealed frequent generalized 4-5 Hz spike and wave, polyspike and wave discharges with bifrontal predominance (Fig1).

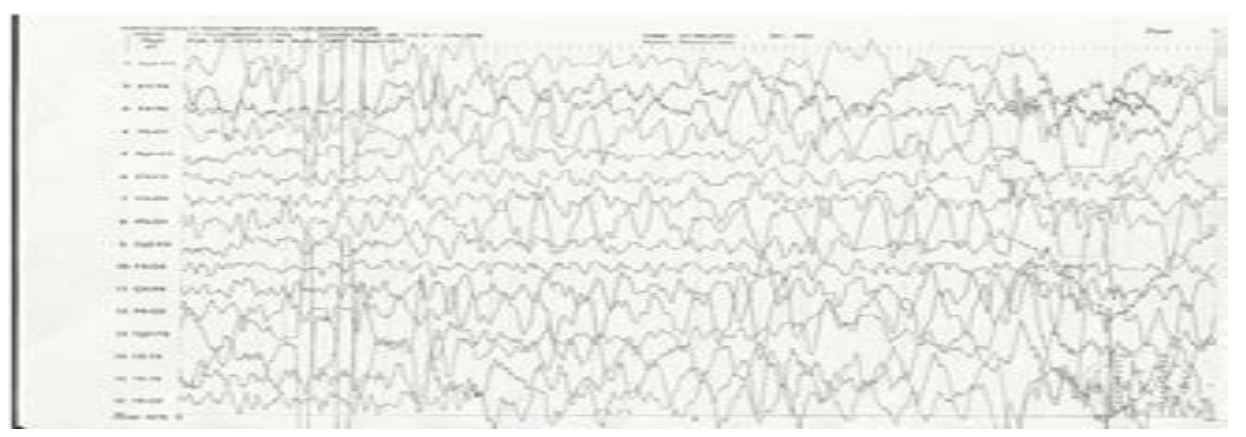

Fig-1: EEG during abdominal pain: generalized spikes

Similar discharges were seen during photic stimulation and sleep. MRI Brain was normal. She was started on Sodium Valproate @ $10 \mathrm{mg} / \mathrm{kg} /$ day in two divided dose and increased to $15 \mathrm{mg} / \mathrm{kg}$ on follow up. Pain occurred during first 1 week of treatment but frequency significantly decreased. There was no pain after 1 month follow up. Repeat EEG after 1 month was normal (Fig2). Thus, diagnosis of abdominal epilepsy was confirmed. Presently child is well on one-year follow-up.

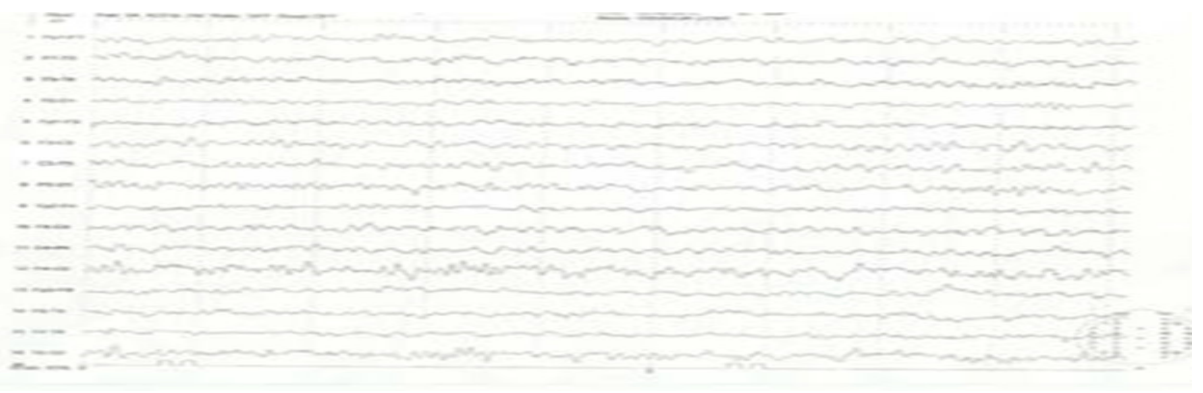

Fig-2: EEG after treatment (normal EEG)

\section{Discussion}

Detailed history and careful clinical examination is a must to evaluate a case of recurrent abdominal pain. There are several "red flag" symptoms and signs like weight loss, reduced growth, significant vomiting, chronic severe diarrhea, bleeding per-rectum, hematemesis, unexplained fever which alert about potential diagnosis. First line screening investigations usually do not reveal anything.Further investigative workup should be guided by a revised history and pain diary on follow-up.Invasive investigations and repeated treatment with de-worming, laxatives, antibiotics, PPI, analgesics and antispasmodics is not helpful and should be avoided. Abdominal Epilepsy is a rare cause of recurrent abdominal pain. Only 36 cases have been reported in the English literature in the last thirty-four years [6]. Frequently observed gastrointestinal symptoms are pain abdomen, nausea and vomiting while the most common neurological symptoms include lethargy, confusion and sleep following pain episode, observed in at least some of the pain episodes.

It is characterized by following diagnostic criteria[7].

1. Otherwise unexplained, paroxysmal GI symptoms

2. Symptoms of CNS disturbance 
3. Abnormal EEG with finding specific for seizure disorder

4. Improvement with anticonvulsant medication

The pathophysiology of abdominal epilepsy still remains unknown. The EEG often shows runs of high voltage slow waves, generalized spikes, and wave discharges or local abnormalities particularly in temporal lobe. Most studies show improvement with carbamazepine or ox carbamazepine as usually the focus lies in temporal lobe. Some studies have also shown use of phenytoin or valproate. Role of particular antiepileptic drug in abdominal epilepsy have not been extensively studied yet. EEG is usually helpful in supporting the clinical diagnosis of abdominal epilepsy [8]. Recording of normal EEG after treatment is a must for diagnosis. Abdominal Epilepsy needs to be differentiated from Irritable bowel syndrome and abdominal Migraine (Table1).

Table-1: Difference between Abdominal epilepsy and abdominal migraine

\begin{tabular}{|c|c|}
\hline Abdominal Epilepsy & Abdominal Migraine \\
\hline $\begin{array}{c}\text { Pain is abrupt in onset with relatively short } \\
\text { duration of episode. }\end{array}$ & $\begin{array}{c}\text { Pain episodes separated by weeks or months. At least 6- } \\
\text { month period before diagnosis }\end{array}$ \\
\hline $\begin{array}{c}\text { Pain is mostly periumbilical or epigastric. Rarely } \\
\text { spreads to involve other body parts }\end{array}$ & Pain may be periumbilical, midline or diffuse. \\
\hline $\begin{array}{c}\text { Pain is followed by post ictal sleep or dizziness or } \\
\text { lethargy }\end{array}$ & No such episode \\
\hline Not functional disorder & A functional disorder diagnosed by ROME III H2c criteria \\
\hline
\end{tabular}

Although its abdominal symptoms may be similar to those of the irritable bowel syndrome, it may be distinguished from the latter condition by the presence of altered consciousness during some of the attacks, a tendency toward tiredness after an attack, and by an abnormal EEG.

\section{Conclusion}

Abdominal epilepsy despite being rare is an easily treatable cause of paroxysmal abdominal pain. Disorientation during an episode of pain followed by exhaustion and sleep is an important clue to diagnosis. Meticulous history taking, detailed record of pain episode and EEG can guide us towards a definitive diagnosis.

Funding: Nil, Conflict of interest: None initiated, Perission from IRB: Yes

\section{References}

1. Apley J, Naish N. Recurrent abdominal pains: a field survey of 1,000 school children. Arch Dis Child. 1958 Apr; 33(168):165-70.

2. Zinkin NT, Peppercorn MA. Abdominal epilepsy. Best Pract Res Clin Gastroenterol. 2005 Apr;19(2):26374. DOI:10.1016/j.bpg.2004.10.001

3. Magon P. Abdominal epilepsy misdiagnosed as peptic ulcer pain. Indian J Pediatr. 2010 Aug;77(8):916. doi: 10.1007/s12098-010-0141-y.
4. Mondal R, Sarkar S, Bag T, et al. A pediatric case series of abdominal epilepsy. World J Pediatr. 2014 Feb; 10 (1): 80-2. doi: 10.1007/s12519-014-0457-1. Epub 2014 Jan 25.

5. Dutta SR, Hazarika I, Chakravarty BP. Abdominal epilepsy, an uncommon cause of recurrent abdominal pain: a brief report. Gut. 2007 Mar; 56 (3):439-41. DOI:10.1136/gut.2006.094250

6. Dutta SR, Hazarika I, Chakravarty BP. Abdominal epilepsy, an uncommon cause of recurrent abdominal pain: a brief report. Gut. 2007 Mar;56(3):439-41. DOI:10.1136/gut.2006.094250

7. Mpondo BC, Mwasada G, Nyundo AA. Abdominal epilepsy, an uncommon cause of chronic and recurrent abdominal pain: a case report. Clinical case reports. 2016 Dec 1;4(12):1117-9.

8. Schade GH, Gofman H. Abdominal epilepsy in childhood. Pediatrics. 1960 Jan;25:151-4.

\section{How to cite this article?}

Deswal S, Paul P, Murugan S, Yadav T.P. Abdominal epilepsy- A diagnosis often missed! - A case report. Int J Pediatr Res. 2018;5(11):598-600.doi:10.17511/ijpr.2018.i11.09. 